the bcok, there follows that on Diseases of the Membranes of the Brain. A separate article on Chronic Infantile Meningitis draws attention to a morbid process perhaps not sufficiently recognised by general practitioners, though many cases have now been recorded. Epidemic Cerebrospinal Meningitis has been very well done-so well, indeed, that we do not regret the space occupied, though it would have been open to the author to have dismissed it in a very fow lines, especially after the thorough method in which other kinds of meningitis receive treatment.

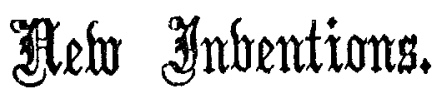

\section{A NEW INHALER.}

I WISH to bring to the notice of the profession a simple adaptable inhaler for administering chloroform and other anæsthetics, which has been used with much success both in the midwifery department and operating theatre of King's College Hospital. The essential principle of the instrument is its adaptability. It consists of a whalebone ring over which an absorbent material is stretched (two layers of lint have been found useful). This ring can be varied in size immediately, and can therefore be made to fit either the largest or smallest face at a moment's delay. A glance at the illustration will show how the size of the loop is altered, by sliding the ends of the whalebone through the hollow handle and fixing them, after the size has been defined, by two set screws furnished for that purpose. When not in use the whalebone can be detached from the handle, coiled up in a ring, and packed away, together with the handle, in a very compact and flexible case. The instrument itself is inexpensive; it is light, though solidly constructed. In children's operations, such as those for harelip and cleft palate, this adaptable inhaler has proved specially useful. It is made by Matthews Brothers, of 10 , New Oxford-street, W.C.

$$
\text { G. L. Cheathe, }
$$

House-Surgeon, King's College Hospital.

\section{SANITATION IN INDIA.}

AT the Parkes Museum, on April 19th, Mr. Justice Cunningham delivered a lecture on the above subject, in which he referred to the anxiety expressed by Sir Lyon Playfair in the debate on the Local Government Bill lest the interests of sanitation should be endangered by their transfer from the superintendence of the Local Government Board to bodies less qualified for the task. An analogous question, he observed, presented itself as to Indian sanitation; but the numerical interests concerned were vastly greater and the issues more fundamental. The problem in India was the preservation of 300 millions of people from epidemic and preventable disease and mortality, which at present showed symptoms of increase rather than decline, and the practical question was whether the Government should make any serious attempt to mitigate this evil, or should abandon the attempt as impracticable. Such an abandonment would be the virtual surrender of one of the great functions of 8 civilised Government in promoting the well-being of its subjects, and would be inconsistent with the strenuous efforts made by the Government in other directions to counteract the great destructive agencies of invasion and famine to which it has devoted millions. The views of the sanitary parties in India might be summerised in the following manner:-1. That the mortality of the population is vastly in excess of that of civilised countries, and, in particular, cannot be calculated at less than from 10 to 15 per 1000 in excess of the English rates, an excess making at least $2,500,000$ deaths and $50,000,000$ cases of severe diseases. 2. That this excess, or a large portion of it, is preventable by practical means fairly within human competence. 3. That the existing administrative machinery is powerless to make any impression on this excessive mortality, but that its tendency is rather to intensify. 4. That there are reforms which materially affect it, which might be adopted without grievance to the peopleor detriment to the Government finances. 5. That it is the duty of the Govern. ment to adopt such reforms. As to the excessive mortality, the lecturer pointed out that when a population approached completeness, there were high ratios of 30 per 1000 and more the central provinces ratio being 34 and the north western provinces 32 . There were many large areas with populations of a million and upwards which showed ratios of 40 and 50 per 1000, and many towns and municipalities which showed ratios of $40,60,70,80$, and even higher. Such ratios showed that the laws of health were being contravened on an enormous scale. A curious instance of the extreme prevalence of disease was shown in Calcutta, where out of a population of 415,000 persons no less than 225,000 were treated annually in public medical institutions. Coming next to preventability, experience proved that wherever effective sanitation was carried out the ratio of Indian mortality sank at once to that of England. Coming to particular instances, the extraordinary reduction in the mortality of the European Army from 69 per 1000 to 13 or 14, the invaliding ratio from 43 to 23 , and the cholera mortality from $9 \cdot 24$ to $1 \cdot 17$, showed what sanitation could do in the case of men newly exposed to a tropical climate. The reduction of the mortality in gaols was equally remarkable; it is now about nne-third the former rate; in Madras the extraordinary low ratio of 17.86 per 1000 had been attained. As to the third point, there were, the lecturer admitted, financial difficulties; but, considerable as was the pressure on the Imperial exchequer owing to combination of unfavourable influences, this pressure did not touch the general population, and need not interfere with the expenditure, which would ensure immense improvement. The country was yearly increasing in wealth, as shown by the automatic growth of revenue. In any case, insanitation was far from economical; disease is costly. In Calcutta it had been reckoned that the preventabledisease and mortality cost the population an annual sum which might be capitalised at $£ 750,000$ sterling, or about three times the whole municipal revenue; and for India at large this loss could not be reckoned at less than $£ 80,000,000$, the whole revenue being only $£ 76,000,000$. The reforms adrocated by the Health Society are:-1. A central executive authority, with the necessary expert element to control and assist municipal bodies, as recommended twenty-eight years ago by the Royal Commission. 2, Increased provision for scientific research into the causes of disease. 3. A recurrence to the system in force in 1879 of Government lending to municipalities, and the creation for this purpose of a Government local works stock. 4. More general instruction in sanitation, and the introduction of sanitation into the educational curriculum of civilian officers. 5. The creation of a committee in England who should effectively supervise Indian sanitation, keeping touch both with public bodies in India and with the various sanitary authorities in England, and thus competent to advise authoritatively on matters of principle. In conclusion, the lecturer pointed out that over-population in India was not a mere charge, as there were still $79,000,000$ of cultivable acres not utilised, and the rate of produce might be increased so as to provide for an additional population of $400,000,000$. The proper check on a possibly redundant population was, not to allow it to be devastated by preventable disease, but to raise the general standard of comfort and encourage prudential habits, which would delay premature marriage and check the growth of numbers premature marriage and check the
beyond available means of sustenance. 